\title{
METODE SAVING MATRIX SEBAGAI METODE ALTERNATIF UNTUK EFISIENSI BIAYA DISTRIBUSI (Studi Empirik Pada Perusahaan Angkutan Kayu Gelondongan Di Jawa Tengah)
}

\author{
Suparjo \\ Fakultas Ekonomika dan Bisnis UNTAG Semarang \\ Email: suparjo_ws@yahoo.com
}

\begin{abstract}
Abstrak
Tujuan penelitian ini adalah untuk mendapatkan rute pengiriman produk yang paling tepat dan optimal yang dapat meminimalkan biaya distribusi, dan untuk mengetahui besarnya penghematan biaya distribusi. Populasi dalam penelitian ini adalah data perusahaan angkutan kayu gelondongan di Jawa Tengah, dan sampel penelitian ini adalah data dari 10 perusahaan angkutan kayu gelondongan di bawah Bunga Bangsa Co. Group di 10 kota di Jawa Tengah. Analisa penentuan rute distribusi menggunakan metode Saving Matrix. Hasil peramalan nilai MAPE, MAD, dan MSE terkecil sebesar 0.50697, 0.102956, dan 0.018398. Hasil analisa dengan menggunakan metode Saving Matrix menunjukkan jumlah rute distribusi dapat diturunkan dari 20 rute menjadi 10 rute. Jarak tempuh yang semula sebesar 3890 kilometer dapat direduksi menjadi 2238 kilometer, yang berarti jarak tersebut dapat dipersingkat/lebih hemat sebesar $42.47 \%$ atau sekitar 1652 kilometer. Adanya penurunan rute mengakibatkan biaya distribusi produk menjadi lebih rendah. Biaya semula adalah sebesar Rp22.952.267 turun menjadi Rp12.835.830. Dengan demikian terjadi penghematan biaya saluran distribusi sebesar Rp10,116,437 atau sekitar 44.07\%.
\end{abstract}

Kata kunci: Metoda Saving Matriks, Efisiensi, Biaya Distribusi

\begin{abstract}
The purpose of this research is to get the most appropriate and optimal product delivery route that can minimize distribution cost, and to know the magnitude of distribution cost savings. The population in this study is data of log transportation companies in Central Java, and the sample of this study is data from 10 log transportation companies under Bunga Bangsa Co. Group in 10 cities in Central Java. Analysis of determination of distribution route using Saving Matrix method. The results of forecasting value MAPE, MAD, and the smallest MSE of 0.50697, 0.102956, and 0.018398. The result of analysis using Saving Matrix method shows the number of distribution routes can be derived from 20 routes into 10 routes. The original distance of 3890 kilometers can be reduced to 2238 kilometers, which means that the distance can be shortened / more efficient by $42.47 \%$ or about 1652 kilometers. The decrease of route resulted in lower product distribution cost. The initial cost amounted to Rp22,952,267, down to Rp12,835,830. Thus there is a saving of distribution channel cost of Rp10,116,437 or about $44.07 \%$.
\end{abstract}

Keywords: Saving Matrix Method, Efficiency, Distribution Cost 


\section{PENDAHULUAN}

Seiring berkembangnya teknologi pada saat ini telah mendorong banyak perusahaan untuk menghasilkan produk yang kreatif, inovatif, dan berupaya menghasilkan nilai kompetitif yang lebih tinggi bagi perusahaannya. Pendistribusian merupakan suatu strategi penyaluran produk yang digunakan oleh produsen untuk menyalurkan produknya kepada konsumen agar dapat diterima konsumen dengan cepat, tepat, dan dalam kondisi yang baik (Erlina, 2009).

Pengalokasian produk dan penentuan rute penghantaran barang merupakan hal penting dalam sebuah industri, baik industri yang berskala kecil maupun skala besar. Kesalahan dalam menentukan saluran distribusi dan keterlambatan pengiriman produk dapat menghambat penyaluran produk dari produsen ke konsumen, yang dapat berakibat mereduksi keuntungan perusahaan dan dapat pula mempunyai potensi timbulnya kerugian bagi perusahaan (Badria, 2008).

Dalam upaya meminimasi biaya transportasi distribusi produk, maka perusahaan harus memperhatikan sistem jaringan transportasi yang ada. Sistem jaringan transportasi dapat dilihat dari segi efektivitas, dalam arti selamat, aksesibilitas tinggi, terpadu, kapasitas mencukupi, teratur, lancar, cepat, mudah dicapai, tepat waktu, nyaman, tarif terjangkau, tertib, aman, dan rendah polusi serta dari segi efisiensi dalam arti memiliki utilitas yang tinggi dalam satu kesatuan jaringan sistem transportasi (Istantiningrum, 2010).

$$
\text { Untuk }
$$

permasalahan ini, maka diperlukan sebuah metode yang dapat memberikan biaya pendistribusian produk yang minimal. Metode Savings Matrix adalah metode yang digunakan untuk menentukan rute distribusi produk ke wilayah pemasaran dengan cara menentukan rute distribusi yang harus dilalui dan jumlah kendaraan berdasarkan kapasitas kendaraan agar diperoleh rute terpendek dan biaya transportasi yang minimal. Metode Savings Matrix juga merupakan salah satu teknik yang digunakan untuk menjadwalkan sejumlah kendaraan terbatas dari fasilitas yang memiliki kapasitas maksimum (Erlina, 2009).

Dengan menggunakan Metode Savings Matrix sangat diharapkan dapat membantu mengatasi permasalahanpermasalahan di atas, sehingga perusahaan mampu membuat perencanaan dengan baik di setiap produk yang akan dikirim, baik itu mengenai jumlah produk maupun tujuannya. Pada studi ini obyek penelitiannya adalah perusahaan jasa transportasi kayu gelondongan di Kota Semarang.

\section{TINJAUAN PUSTAKA \\ Manajemen Distribusi}

Distribusi mencakup semua aspek dalam pengiriman produk kepada konsumen. Turner \& Heizer (2000) menyatakan bahwa saluran distribusi adalah suatu jalur yang dilalui oleh arus barang-barang dari produsen ke perantara dan akhirnya sampai kepada pemakai. Selain itu, distribusi juga dapat diartikan sebagai lembaga-lembaga penyalur yang mempunyai kegiatan untuk menyalurkan barang-barang atau jasa-jasa dari produsen ke konsumen.

Produsen harus mempertimbangkan berbagai macam faktor yang sangat berpengaruh dalam pemilihan saluran distribusi. Pemilihan saluran distribusi yang efektif akan mampu mendorong peningkatan penjualan yang diharapkan, sehingga kelangsungan hidup perusahaan dapat terjamin (Lubis, 2004).

Saluran distribusi merupakan salah satu alat bauran pemasaran yang dapat menentukan berhasil tidaknya pemasaran yang dilakukan oleh sebuah perusahaan. Oleh karena itu, sebuah saluran distribusi yang efektif, pastilah dapat lebih menunjang pelaksanaan pemasaran yang efektif pula (Kotler,2006).

Transportasi merupakan faktor yang harus diperhatikan, karena aktivitas 
pengangkutan meliputi proses mengangkut dan memindahkan barang atau produk ke tempat tujuan yang membutuhkan biaya yang tidak sedikit (Salim, 2004). Transportasi didefinisikan sebagai usaha dan kegiatan mengangkut atau membawa barang dan atau penumpang dari suatu tempat ke tempat lainnya. Selain itu, pengangkutan atau pemindahan penumpang atau barang dengan transportasi adalah untuk mencapai tempat tujuan dan menaikkan utilitas atau kegunaan dari barang yang diangkut. Utilitas yang dapat diciptakan oleh transportasi ada dua macam, yaitu utilitas tempat (Place Utility) dan utilitas waktu (Time Utility). Setiap bentuk transportasi terdapat empat unsur pokok transportasi, yaitu jalan, kendaraan dan alat angkutan, tenaga penggerak, serta terminal (Kadir, 2006).

Pada sistem transportasi modern, transportasi merupakan bagian integral dari fungsi dan aktivitas masyarakat. Terdapat hubungan yang sangat erat dengan gaya hidup, jangkauan, lokasi kegiatan produksi, pemenuhan barangbarang, dan pelayanan yang tersedia untuk konsumsi. Semakin berkembangnya peradaban manusia saat ini, mampu membuat transportasi menjadi satu kesatuan mata rantai kehidupan yang sangat berpengaruh dalam pembangunan masyarakat (Petra, 2013).

Dalam suatu jaringan fasilitas, transportasi merupakan suatu rantai mata penghubung. Beberapa tahun terakhir ini, manajemen transportasi mendapat banyak perhatian dari berbagai kalangan perusahaan. Hampir setiap perusahaan dari berbagai ukuran dipastikan mempunyai manajer yang secara penuh bertanggung jawab terhadap pengelolaan program transportasinya. Secara umum, sebuah perusahaan mempunyai tiga alternatif untuk menetapkan kemampuan transportasinya. Alternatif pertama mengenai armada peralatan yang dapat dibeli atau disewa. Kedua, kontrak khusus dapat diatur dengan spesialis transportasi untuk mendapatkan kontrak jasa-jasa pengang- kutan. Ketiga, sebuah perusahaan dapat memperoleh jasa-jasa dari suatu perusahaan transportasi berijin (legally authorized) yang menawarkan pengangkutan dari suatu tempat ke tempat lain dengan biaya tertentu. Ketiga bentuk transportasi ini dikenal sebagai swasta (private), kontrak (contract), dan angkutan umum (common carriage). Jika dilihat dari sudut pandang logistik, ada tiga faktor yang memegang peranan utama dalam menentukan kemampuan pelayanan transportasi, yaitu biaya, kecepatan, dan konsistensi (Bowersox, 1995).

\section{Metode Saving Matriks}

Saving Matrix merupakan metode yang digunakan untuk menentukan jarak, rute, waktu atau ongkos dalam pelaksanaan pengiriman barang dari perusahaan kepada konsumen. Metode ini bertujuan agar pengiriman barang yang sesuai pesanan konsumen dapat dilakukan dengan cara yang efektif dan efisien, sehingga perusahaan dapat menghemat biaya, tenaga, dan waktu pengiriman (Istantiningrum, 2010).

Metode Saving Matrix terdiri dari beberapa langkah. Menurut Istantiningrum (2010) langkah-langkah dalam metode saving matrix adalah sebagai berikut:

1. Menentukan Matriks Jarak

Pada penentuan matriks jarak ini, data jarak antara perusahaan dengan lokasi dan lokasi ke lokasi lainnya sangat diperlukan. Setelah mengetahui koordinat dari masing-masing lokasi, maka jarak antar kedua lokasi tersebut dapat dihitung dengan menggunakan rumus sebagai berikut:

$$
j(1,2)=\sqrt{\left(x_{1}-x_{2}\right)+\left(y_{1}-y_{2}\right)}{ }^{2}
$$

Akan tetapi jika jarak antar kedua koordinat sudah diketahui, maka perhitungan menggunakan rumus tidak digunakan dan menggunakan jarak yang sudah ada.

2. Menentukan Matriks Penghematan (Saving Matrix)

Setelah mengetahui jarak keseluruhan yaitu jarak antara pabrik dengan lokasi 
dan lokasi dengan lokasi yang lainnya, maka dalam langkah ini diasumsikan bahwa setiap lokasi akan dilewati oleh satu truk secara ekslusif. Artinya akan ada beberapa rute yang berbeda yang akan dilewati untuk tujuan masingmasing. Dengan demikian akan ada penghematan apabila ada penggabungan rute yang dinilai satu arah dengan rute yang lainnya. Untuk mencari matriks penghematan dapat digunakan rumus sebagai berikut:

$S(x, y)=J(x, y)+J(x, y)-J(x, y)$

$\mathrm{S}(\mathrm{x}, \mathrm{y})$ merupakan penghematan jarak yaitu dari penggabungan antara rute $\mathrm{x}$ dengan rute $\mathrm{y}$.

3. Pengalokasian Kendaraan dan Rute Berdasarkan Lokasi

Setelah matriks penghematan diketahui, maka langkah selanjutnya adalah pengalokasian lokasi ke rute atau kendaraan. Artinya dalam langkah ini akan ditentukan rute pengiriman baru berdasarkan atas penggabungan rute pada langkah kedua di atas. Hasilnya adalah pengiriman lokasi 1 dan lokasi 2 akan dilakukan dengan menggunakan 1 rute.

4. Pengurutan Lokasi Tujuan Dalam Suatu Rute

Langkah ini menentukan urutan kunjungan. Ada beberapa metode dalam menentukan urutan kunjungan, yaitu:

a. Metode Nearest Insert

Metode ini menentukan urutan kunjungan dengan mengutamakan lokasi yang kalau dimasukkan ke dalam rute yang sudah ada menghasilkan jarak yang minimum.

b. Metode Nearest Neighbor

Metode ini menentukan kunjungan dengan mengutamakan lokasi yang jaraknya paling dekat dengan lokasi yang dikunjungi terakhir.
5. Penjadwalan Produksi

Manfaat penjadwalan salah satunya adalah agar dalam pengiriman barang dapat sesuai dengan waktu dan porsi yang telah ditentukan. Penjadwalan juga mempunyai tujuan. Tujuan dalam penjadwalan adalah agar dalam pengiriman barang dilakukan secara berurutan sesuai dengan jadwal yang dibuat. Jadwal tersebut berupa catatan waktu yang dituangkan menjadi satu kalender yang sangat dibutuhkan oleh para pelaksana. Beberapa hasil dari penjadwalan salah satunya adalah pengiriman sesuai rute yang telah tersedia di dalam tabel hasil pengelompokan sehingga pengiriman tidak melebihi kapasitas dalam mengirim (Istantiningrum, 2010).

\section{METODE PENELITIAN Data Penelitian}

Data yang digunakan dalam penelitian ini adalah sebagai berikut:

1. Data Primer

Adalah data yang khusus diambil dengan tujuan semata-mata hanya untuk penelitian, diperoleh dari hasil observasi dan wawancara di lapangan.

2. Data Sekunder

Adalah data yang diperoleh dari referensi yang berasal dari berbagai macam sumber seperti perusahaan, internet, buku dan literatur lainnya.

\section{Lokasi dan Waktu Penelitian}

Penelitian ini dilakukan pada perusahaan jasa angkutan kayu gelondongan di Jawa Tengah dengan mengambil sampel perusahaan-perusahaan dibawah bendera Bunga Bangsa Group Co. Semarang yang memiliki 10 (sepuluh) perusahaan pengangkutan barang/kayu gelondongan. Penelitian dilakukan selama 5 bulan dan dilaksanakan pada bulan Juli 2016 - November 2016. 


\section{Prosedur Pengumpulan Data}

\section{Riset Kepustakaan}

Dengan cara mempelajari berbagai teori dan alat analisis yang bersumber dari buku-buku, diktat, literatur, dan referensireferensi yang relevan.

Riset Lapangan

\section{a. Observasi}

Dilakukan pada perusahaan-perusahaan di bawah Bunga Bangsa Group Co. Semarang dengan melakukan pengamatan langsung di lapangan dan pencatatan data yang diperlukan.

b. Wawancara

Dilakukan dengan mengadakan tanya jawab langsung kepada petugas perusahaan untuk memperoleh data yang lebih akurat.

\section{Teknik Analisis}

Metode Savings Matrix adalah metode yang digunakan untuk menentukan rute distribusi produk ke wilayah pemasaran dengan cara menentukan rute distribusi yang harus dilalui dan jumlah kendaraan berdasarkan kapasitas kendaraan agar diperoleh rute terpendek dan biaya transportasi yang minimal. Metode Savings Matrix juga merupakan salah satu teknik yang digunakan untuk menjadwalkan sejumlah kendaraan terbatas dari fasilitas yang memiliki kapasitas maksimum (Erlina, 2009).

Dengan menggunakan Metode Savings Matrix diharapkan dapat menjawab permasalahan penelitian, dan perusahaan mampu membuat perencanaan di setiap produk yang akan dikirim, baik itu mengenai jumlah produk maupun tujuannya.

Software yang digunakan untuk peramalan Minitab 16 dapat berguna untuk proses pemasukan data, pembuatan grafik, analisis statistik, dan proses peramalan.

\section{HASIL PENELITIAN}

\section{Data Permintaan Konsumen}

Tabel 1 adalah data rata-rata permintaan konsumen dari 10 (sepuluh) perusahaan angkutan kayu gelondongan dari bulan Oktober 2015 hingga bulan September 2016.

\section{Rute Awal}

Dari 10 perusahaan memiliki alat angkut berupa Truck sejumlah 96 buah. Masingmasing alat angkut mempunyai kapasitas maksimal $15000 \mathrm{Kg}$. Rute awal perusahaan berjumlah 20 rute. Rute awal perusahaan adalah gudang-konsumen-gudang. Tabel 2 adalah data rata-rata rute awal pengiriman produk beserta data jarak pada setiap rute.

Total jarak yang dihasilkan pada rute awal ini adalah sebanyak 3890 kilometer. Jarak pada rute awal tersebut dinilai terlalu panjang dan harus dipangkas agar tidak menimbulkan waktu pengiriman yang lama dan biaya transportasi yang tinggi.

\section{Data Jarak Konsumen}

Data jarak antara gudang dengan konsumen dan jarak antar konsumen ditampilkan pada Tabel 3.

\section{Elemen Biaya Transportasi}

Elemen biaya yang digunakan pada perusahaan ini adalah seperti pada Tabel 4.

\section{Biaya Transportasi Awal}

Biaya transportasi awal dihitung berdasarkan rute awal perusahaan. Perhitungannya menggunakan data elemen biaya pada Tabel 4. Hasil perhitungan biaya transportasi awal pada setiap rute dapat dijelaskan pada Tabel 5 .

Pada Tabel 5 disajikan biaya transportasi produk di masing-masing rute. Total biaya yang dikeluarkan perusahaan di dalam proses distribusi berdasarkan rute awal adalah sebesar Rp. 22.952.267. Ternyata, biaya tersebut dapat dipandang terlalu besar. Oleh karena itu, biaya transportasi pada rute awal di atas harus dapat diminimalisasi.

\section{Identifikasi Matriks Penghematan (Saving Matrix)}

Matrik penghematan diperoleh dengan menggabungkan dua rute konsumen atau lebih secara bersamaan. 
Penggabungan tersebut disesuaikan dengan jumlah permintaan konsumen. Jumlah penggabungan permintaan konsumen tidak diperbolehkan melebihi kapasitas alat angkut. Tabel matrik penghematan dapat dilihat pada Tabel 6.

\section{Penggabungan Rute Saving Matrix}

Pengalokasian konsumen ke dalam satu rute yang sama dilakukan berdasarkan hasil perhitungan matriks penghematan. Matriks penghematan tersebut dibuat berurutan dimulai dari penghematan tertinggi hingga terendah.

\section{Alokasi Permintaan Konsumen}

Alokasi permintaan konsumen dapat dimulai dengan melihat nilai penghematan terbesar. Alokasi tiap konsumen yang berbeda bisa digabungkan sampai pada batas kapasitas truk yang tersedia di perusahaan. Hasil penggabungan rute dapat dijelaskan pada Tabel 8. Tabel 8 menunjukkan adanya penggabungan rute. Jumlah rute semula adalah 20. Setelah digabungkan, jumlah rute menjadi 10 . Total beban yang diangkut masih di bawah batas maksimal kapasitas alat angkut yaitu $15000 \mathrm{Kg}$. Dengan demikian, kesepuluh rute tersebut dapat digunakan.

\section{Penentuan Rute dan Biaya Transportasi}

Penentuan rute baru dapat dilakukan dengan metode Nearest Insert (konsumen yang menghasilkan tambahan jarak minimum), yang hasilnya dapat dilihat pada Tabel 9. Dengan menggunakan metode Nearest Insert, total jarak yang ditempuh adalah 2415 kilometer dan jumlah biaya yang dikeluarkan sebesar Rp. 12.800.800.

\section{Plotting Data Permintaan}

Langkah awal dalam melakukan proses peramalan yaitu plotting data ratarata permintaan aktual sesuai dengan data masa lalu yaitu data selama 12 bulan menggunakan software Minitab 16. Plotting data bertujuan untuk menentukan metode peramalan yang akan digunakan (Kalekar, 2004). Grafik plotting data rata- rata permintaan adalah seperti pada Gambar 1.

Berdasarkan hasil plotting data permintaan masa lalu yang dimiliki, maka pola yang terbentuk adalah pola data trend. Hal tersebut ditandai dengan adanya kecenderungan arah data bergerak naik atau turun pada jangka panjang (Raharja, et al., 2013). Dengan demikian, teknik peramalan yang tepat digunakan adalah teknik peramalan untuk data trend.

\section{Hasil Peramalan Permintaan Konsumen}

Rata-rata hasil peramalan permintaan konsumen selama satu tahun ke depan dengan menggunakan metode Linear Regression dapat dijelaskan pada Tabel 10. Berdasarkan hasil peramalan dengan menggunakan metode Linear Regression, rata-rata permintaan konsumen sangatlah bervariasi.

\section{Uji Verifikasi dengan MRC (Moving Range Chart)}

Uji verifikasi hasil peramalan diperlukan untuk mengetahui apakah metode peramalan yang digunakan representatif terhadap data atau tidak. Selain itu, Moving Range Chart digunakan untuk membandingkan nilai pengamatan aktual dengan nilai peramalan dari suatu permintaan (Fauzan \& Rahmayanti, 2013). Grafiknya moving range chart regresi time series dapat dijelaskan pada Gambar 2. Berdasarkan grafik tersebut, terlihat bahwa tidak ada data yang berada di luar batas kontrol atas maupun batas kontrol bawah. Dengan demikian, metode Linear Regression dapat dikatakan sesuai atau representatif terhadap penelitian ini.

\section{Rute dan Biaya Transportasi Baru (Usulan)}

Rute baru dan biaya transportasi berikut ini adalah berdasarkan hasil peramalan permintaan bulan Januari 2016 hingga bulan Maret 2017. Rute inilah yang nantinya akan digunakan sebagai usulan ke 
perusahaan, sebagaimana dijelaskan pada Tabel 11.

Jumlah rute semula adalah 20. Setelah digabungkan, jumlah rute menjadi 10. Total beban yang diangkut masih di bawah batas maksimal kapasitas alat angkut yaitu $15000 \mathrm{Kg}$. Dengan demikian, kesepuluh rute tersebut dapat digunakan.

Dengan menggunakan metode Nearest Neighbor, total jarak yang ditempuh adalah 4842.8 kilometer dan jumlah biaya yang dikeluarkan sebesar Rp. 30.905.270 (Tabel 12).

Tabel 1. Data Rata-rata Permintaan Konsumen

\begin{tabular}{cccccc}
\hline No & Kode Konsumen & Permintaan rata-rata & No & Kode Konsumen & Permintaan rata-rata \\
\hline 1 & A & 614 & 11 & A & 585 \\
2 & B & 643 & 12 & B & 522 \\
3 & C & 550 & 13 & C & 614 \\
4 & D & 734 & 14 & D & 462 \\
5 & E & 736 & 15 & E & 751 \\
6 & F & 601 & 16 & F & 838 \\
7 & G & 654 & 17 & G & 512 \\
8 & H & 488 & 18 & H & 815 \\
9 & I & 631 & 19 & I & 682 \\
10 & J & 691 & 20 & J & 621 \\
\hline
\end{tabular}

Sumber: Bunga Bangsa Group.Co

Tabel 2. Rute Awal dan Jarak

\begin{tabular}{cccccc}
\hline No & Konsumen & Jarak $(\mathbf{K m})$ & No & Konsumen & Jarak ( Km) \\
\hline 1 & G-A-G & 56 & 11 & G-K-G & 300 \\
2 & G-B-G & 94 & 12 & G-L-G & 202 \\
3 & G-C-G & 190 & 13 & G-M-G & 456 \\
4 & G-D-G & 216 & 14 & G-N-G & 154 \\
5 & G-E-G & 460 & 15 & G-O-G & 226 \\
6 & G-F-G & 160 & 16 & G-P-G & 92 \\
7 & G-G-G & 64 & 17 & G-Q-G & 128 \\
8 & G-H-G & 106 & 18 & G-R-G & 240 \\
9 & G-I-G & 54 & 19 & G-S-G & 282 \\
10 & G-J-G & 108 & 20 & G-T-G & 302 \\
\hline
\end{tabular}

Sumber: Bunga Bangsa Group.Co 
Tabel 3. Jarak Konsumen (Km)

\begin{tabular}{ccccccccc}
\hline & GDG & A & B & C & D & E & F & G \\
\hline GDG & 0 & 28 & 47 & 95 & 108 & 230 & 80 & 32 \\
A & 28 & 0 & 18 & 48 & 79 & 203 & 44 & 58 \\
B & 47 & 18 & 0 & 40 & 82 & 205 & 40 & 24 \\
C & 95 & 48 & 40 & 0 & 35 & 233 & 79 & 109 \\
D & 108 & 79 & 82 & 35 & 0 & 261 & 108 & 113 \\
E & 230 & 203 & 205 & 233 & 261 & 0 & 177 & 222 \\
F & 80 & 44 & 40 & 79 & 108 & 177 & 0 & 78 \\
G & 32 & 58 & 24 & 109 & 113 & 222 & 78 & 0 \\
H & 53 & 79 & 82 & 123 & 155 & 175 & 44 & 39 \\
I & 27 & 53 & 73 & 103 & 92 & 257 & 89 & 33 \\
J & 54 & 65 & 86 & 117 & 86 & 272 & 117 & 66 \\
K & 150 & 129 & 124 & 165 & 209 & 82 & 87 & 144 \\
L & 101 & 90 & 85 & 125 & 154 & 130 & 47 & 106 \\
M & 228 & 186 & 175 & 202 & 266 & 40 & 159 & 213 \\
N & 77 & 47 & 37 & 78 & 105 & 158 & 22 & 100 \\
O & 113 & 104 & 124 & 155 & 152 & 273 & 140 & 55 \\
P & 46 & 73 & 92 & 100 & 108 & 263 & 109 & 52 \\
Q & 64 & 69 & 97 & 61 & 34 & 270 & 111 & 95 \\
R & 120 & 94 & 75 & 102 & 144 & 122 & 50 & 130 \\
S & 141 & 112 & 103 & 76 & 44 & 308 & 141 & 137 \\
T & 151 & 114 & 119 & 92 & 70 & 324 & 167 & 143 \\
\hline Su
\end{tabular}

Sumber: Bunga Bangsa Group.Co

Tabel 4. Elemen Biaya

\begin{tabular}{cll}
\hline No & \multicolumn{1}{c}{ Elemen Biaya } & \multicolumn{1}{c}{ Biaya (Rp) } \\
\hline 1 & BBM/Liter & 5.600 \\
2 & TENAGA KERJA/hr & 1.250 .000 \\
3 & UANG MAKAN/hr & 100.000 \\
4 & RETRIBUSI & 200.000 \\
5 & MAINTAINANCE & 300.000 \\
\hline
\end{tabular}

Sumber: Bunga Bangsa Group.Co

Keterangan:

a. 1 liter solar mampu menempuh 15 kilometer.

b. Biaya retribusi meliputi biaya tol, parkir, pungutan, dll. 
Tabel 5. Biaya Transportasi Awal

\begin{tabular}{|c|c|c|c|c|c|c|}
\hline No & Konsumen & Jarak (Km) & $\begin{array}{c}\text { Biaya Tenaga } \\
\text { Kerja }\end{array}$ & Maintenance & $\begin{array}{l}\text { BBM,Retribusi, } \\
\text { Uang Makan }\end{array}$ & Total \\
\hline 1 & G-A-G & 56 & \multirow{2}{*}{ Rp1,250,000 } & \multirow{2}{*}{ Rp300,000 } & Rp320,906.67 & \multirow{2}{*}{ Rp2,206,000 } \\
\hline 2 & G-B-G & 94 & & & Rp335,093.33 & \\
\hline 3 & G-C-G & 190 & \multirow{2}{*}{ Rp1,250,000 } & \multirow{2}{*}{ Rp300,000 } & Rp370,933.33 & \multirow{2}{*}{$\mathrm{Rp} 2,301,573$} \\
\hline 4 & G-D-G & 216 & & & Rp380,640.00 & \\
\hline 5 & G-E-G & 460 & \multirow{2}{*}{ Rp1,250,000 } & \multirow{2}{*}{ Rp300,000 } & Rp471,733.33 & \multirow{2}{*}{$\mathrm{Rp} 2,381,467$} \\
\hline 6 & G-F-G & 160 & & & Rp359,733.33 & \\
\hline 7 & G-G-G & 64 & \multirow{2}{*}{ Rp1,250,000 } & \multirow{2}{*}{ Rp300,000 } & Rp323,893.33 & \multirow{2}{*}{$\operatorname{Rp} 2,213,467$} \\
\hline 8 & G-H-G & 106 & & & Rp339,573.33 & \\
\hline 9 & G-I-G & 54 & \multirow{2}{*}{ Rp1,250,000 } & \multirow{2}{*}{ Rp300,000 } & Rp320,160.00 & \multirow{2}{*}{$\mathrm{Rp} 2,210,480$} \\
\hline 10 & G-J-G & 108 & & & Rp340,320.00 & \\
\hline 11 & G-K-G & 300 & \multirow{2}{*}{ Rp1,250,000 } & \multirow{2}{*}{ Rp300,000 } & Rp412,000.00 & \multirow{2}{*}{$\mathrm{Rp} 2,337,413$} \\
\hline 12 & G-L-G & 202 & & & Rp375,413.33 & \\
\hline 13 & G-M-G & 456 & \multirow{2}{*}{ Rp1,250,000 } & \multirow{2}{*}{ Rp300,000 } & $\mathrm{Rp} 470,240.00$ & \multirow{2}{*}{$\mathrm{Rp} 2,377,733$} \\
\hline 14 & G-N-G & 154 & & & Rp357,493.33 & \\
\hline 15 & G-O-G & 226 & \multirow{2}{*}{ Rp1,250,000 } & \multirow{2}{*}{ Rp300,000 } & Rp384,373.33 & \multirow{2}{*}{$\operatorname{Rp} 2,268,720$} \\
\hline 16 & G-P-G & 92 & & & Rp334,346.67 & \\
\hline 17 & G-Q-G & 128 & \multirow{2}{*}{ Rp1,250,000 } & \multirow{2}{*}{ Rp300,000 } & Rp347,786.67 & \multirow{2}{*}{ Rp2,287,387 } \\
\hline 18 & G-R-G & 240 & & & Rp389,600.00 & \\
\hline 19 & G-S-G & 282 & \multirow{2}{*}{$\mathrm{Rp} 1,250,000$} & \multirow{2}{*}{ Rp300,000 } & $\mathrm{Rp} 405,280.00$ & \multirow{2}{*}{ Rp2,368,027 } \\
\hline 20 & G-T-G & 302 & & & Rp412,746.67 & \\
\hline & COTAL & 3890 & & Rp2 & $, 952,267$ & \\
\hline
\end{tabular}

Tabel 6. Matriks Untuk Penghematan

\begin{tabular}{ccccccccc}
\hline & $\mathrm{A}$ & $\mathrm{B}$ & $\mathrm{C}$ & $\mathrm{D}$ & $\mathrm{E}$ & $\mathrm{F}$ & $\mathrm{G}$ & $\mathrm{H}$ \\
\hline $\mathrm{A}$ & 0 & & & & & & & \\
$\mathrm{~B}$ & 57 & 0 & & & & & & \\
$\mathrm{C}$ & 75 & 102 & 0 & & & & & \\
$\mathrm{D}$ & 57 & 73 & 168 & 0 & & & & \\
$\mathrm{E}$ & 55 & 72 & 92 & 77 & 0 & & & \\
$\mathrm{~F}$ & 64 & 87 & 96 & 80 & 133 & 0 & & \\
$\mathrm{G}$ & 2 & 55 & 18 & 27 & 40 & 34 & 0 & \\
$\mathrm{H}$ & 2 & 18 & 25 & 6 & 108 & 89 & 46 & 0 \\
$\mathrm{I}$ & 2 & 1 & 19 & 43 & 0 & 18 & 26 & 66 \\
$\mathrm{~J}$ & 17 & 15 & 32 & 76 & 12 & 17 & 20 & 15 \\
$\mathrm{~K}$ & 49 & 73 & 80 & 49 & 298 & 143 & 38 & 103 \\
$\mathrm{~L}$ & 39 & 63 & 71 & 55 & 201 & 134 & 27 & 92 \\
$\mathrm{M}$ & 70 & 100 & 121 & 70 & 418 & 149 & 47 & 111 \\
$\mathrm{~N}$ & 58 & 87 & 94 & 80 & 149 & 135 & 9 & 65 \\
$\mathrm{O}$ & 37 & 36 & 53 & 69 & 70 & 53 & 90 & 72 \\
$\mathrm{P}$ & 1 & 1 & 41 & 46 & 13 & 17 & 26 & 14 \\
$\mathrm{Q}$ & 23 & 14 & 98 & 138 & 24 & 33 & 1 & -5 \\
$\mathrm{R}$ & 54 & 92 & 113 & 84 & 228 & 150 & 22 & 55 \\
$\mathrm{~S}$ & 57 & 85 & 160 & 205 & 63 & 80 & 36 & 10 \\
$\mathrm{~T}$ & 65 & 79 & 154 & 189 & 57 & 64 & 40 & 5 \\
\hline
\end{tabular}


Tabel 7. Matrik Penghematan

\begin{tabular}{cccccccc}
\hline Peringkat & Nilai & Peringkat & Nilai & Peringkat & Nilai & Peringkat & Nilai \\
\hline 1 & 418 & 11 & 201 & 21 & 149 & 31 & 111 \\
2 & 305 & 12 & 189 & 22 & 143 & 32 & 111 \\
3 & 298 & 13 & 168 & 23 & 138 & 33 & 110 \\
4 & 264 & 14 & 165 & 24 & 135 & 34 & 110 \\
5 & 245 & 15 & 164 & 25 & 134 & 35 & 109 \\
6 & 228 & 16 & 160 & 26 & 133 & 36 & 108 \\
7 & 208 & 17 & 157 & 27 & 132 & 37 & 104 \\
8 & 205 & 18 & 154 & 28 & 122 & 38 & 103 \\
9 & 202 & 19 & 150 & 29 & 121 & 39 & 102 \\
10 & 202 & 20 & 149 & 30 & 113 & 40 & 100 \\
\hline
\end{tabular}

Tabel 8. Alokasi Permintaan Konsumen

\begin{tabular}{cccccc}
\hline No & Rute & Konsumen & $\begin{array}{c}\text { Total Beban Order } \\
(\mathrm{Kg})\end{array}$ & Keterangan & $\begin{array}{c}\text { Kapasitas Alat } \\
\text { Angkut }\end{array}$ \\
\hline 1 & Rute 1 & E,M & 13500 & OK & 15000 \\
2 & Rute 2 & O,T & 13720 & OK & 15000 \\
3 & Rute 3 & D,S & 14160 & OK & 15000 \\
4 & Rute 4 & K,L & 11070 & OK & 15000 \\
5 & Rute 5 & R,N & 12770 & OK & 15000 \\
6 & Rute 6 & B,C & 11930 & OK & 15000 \\
7 & Rute 7 & F,H & 10890 & OK & 15000 \\
8 & Rute 8 & J,Q & 12030 & OK & 15000 \\
9 & Rute 9 & I,P & 14690 & OK & 15000 \\
10 & Rute 10 & G,A & 12680 & OK & 15000 \\
\hline
\end{tabular}

Tabel 9. Metode Nearest

\begin{tabular}{|c|c|c|c|c|c|c|c|}
\hline No & Rute & $\begin{array}{c}\text { Jadwal } \\
\text { Pengiriman }\end{array}$ & $\begin{array}{l}\text { Total Jarak } \\
\text { (KM) }\end{array}$ & $\begin{array}{c}\text { BBM, } \\
\text { Retribusi, } \\
\text { Makan }\end{array}$ & Tenaga Kerja & Perawatan & Total Biaya \\
\hline 1 & Rute 1 & G-M-E-G & 498 & Rp485,920 & \multirow{2}{*}{ Rp1,500,000 } & \multirow{2}{*}{ Rp300,000 } & \multirow{2}{*}{$\mathrm{Rp} 2,744,960$} \\
\hline 2 & Rute 2 & G-O-T-G & 426 & Rp459,040 & & & \\
\hline 3 & Rute 3 & G-D-S-G & 94 & Rp335,093 & \multirow{2}{*}{ Rp1,500,000 } & \multirow{2}{*}{ Rp300,000 } & \multirow{2}{*}{ Rp2,506,027 } \\
\hline 4 & Rute 4 & G-L-K-G & 190 & Rp370,933 & & & \\
\hline 5 & Rute 5 & G-N-R-G & 237 & Rp388,480 & \multirow{2}{*}{ Rp1,500,000 } & \multirow{2}{*}{ Rp300,000 } & \multirow{2}{*}{ Rp2,556,427 } \\
\hline 6 & Rute 6 & G-B-C-G & 182 & Rp367,947 & & & \\
\hline 7 & Rute 7 & G-H-F-G & 117 & Rp343,680 & \multirow{2}{*}{ Rp1,500,000 } & \multirow{2}{*}{ Rp300,000 } & \multirow{2}{*}{$\operatorname{Rp} 2,506,400$} \\
\hline 8 & Rute 8 & G-J-Q-G & 168 & Rp362,720 & & & \\
\hline 9 & Rute 9 & G-I-P-G & 94 & Rp335,093 & \multirow{2}{*}{ Rp1,500,000 } & \multirow{2}{*}{ Rp300,000 } & \multirow{2}{*}{ Rp2,486,987 } \\
\hline 10 & Rute 10 & G-A-G-G & 139 & Rp351,893 & & & \\
\hline \multicolumn{3}{|c|}{ Total } & 2145 & \multicolumn{4}{|c|}{ Rp12,800,800 } \\
\hline
\end{tabular}




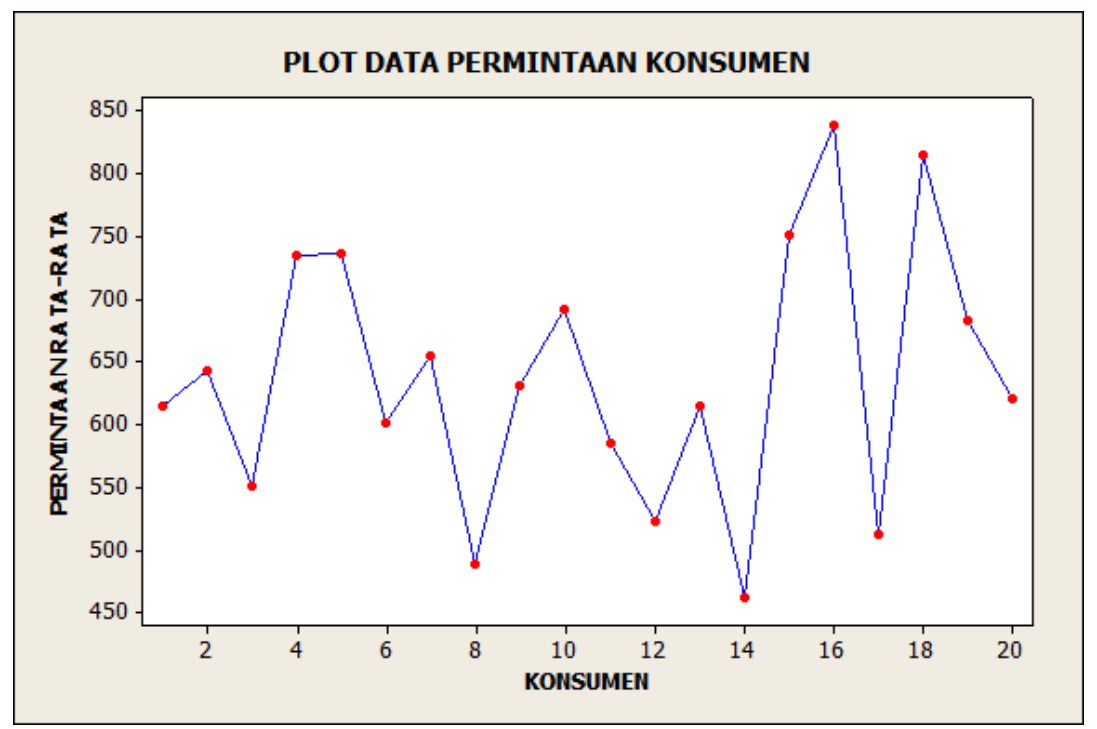

Gambar 1. Plotting Data Rata-Rata Permintaan

Tabel 10. Alokasi Permintaan Konsumen

\begin{tabular}{cccc}
\hline Konsumen & Hasil Peramalan $(\mathrm{Kg})$ & Konsumen & Hasil Peramalan $(\mathrm{Kg})$ \\
\hline A & 10070 & $\mathrm{~K}$ & 7320 \\
B & 5790 & $\mathrm{~L}$ & 5440 \\
C & 4220 & $\mathrm{M}$ & 7900 \\
D & 5820 & $\mathrm{~N}$ & 4880 \\
E & 5820 & $\mathrm{O}$ & 6150 \\
F & 8770 & $\mathrm{P}$ & 7030 \\
G & 6980 & $\mathrm{Q}$ & 4050 \\
H & 1410 & $\mathrm{R}$ & 5080 \\
I & 3610 & $\mathrm{~S}$ & 7250 \\
J & 7210 & $\mathrm{~T}$ & 4390 \\
\hline
\end{tabular}

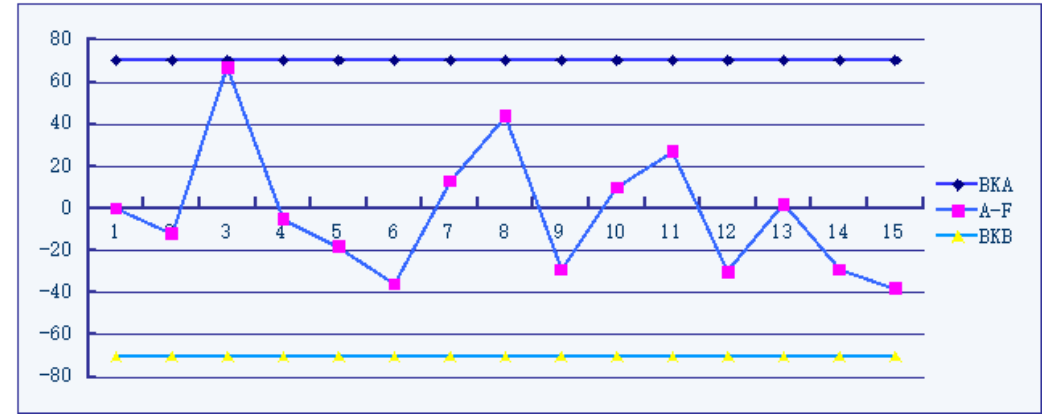

Gambar 2. Moving Range Chart Regresi Time Series 
Tabel 11. Alokasi Konsumen Hasil Peramalan

\begin{tabular}{cccccc}
\hline No & Rute & Konsumen & $\begin{array}{c}\text { Total Beban } \\
\text { Order (Kg) }\end{array}$ & Keterangan & $\begin{array}{c}\text { Kapasitas } \\
\text { Alat Angkut }\end{array}$ \\
\hline 1 & Rute 1 & E,M & 13720 & OKE & 15000 \\
2 & Rute 2 & O,T & 10540 & OKE & 15000 \\
3 & Rute 3 & D,S & 13070 & OKE & 15000 \\
4 & Rute 4 & K,L & 12760 & OKE & 15000 \\
5 & Rute 5 & N,R & 10960 & OKE & 15000 \\
6 & Rute 6 & B,C & 11010 & OKE & 15000 \\
7 & Rute 7 & F,H & 10180 & OKE & 15000 \\
8 & Rute 8 & J,P & 14240 & OKE & 15000 \\
9 & Rute 9 & G,I & 10590 & OKE & 15000 \\
10 & Rute 10 & A,Q & 14120 & OKE & 15000 \\
\hline
\end{tabular}

Tabel 12. Rute dan Biaya Transportasi Baru (Hasil Peramalan)

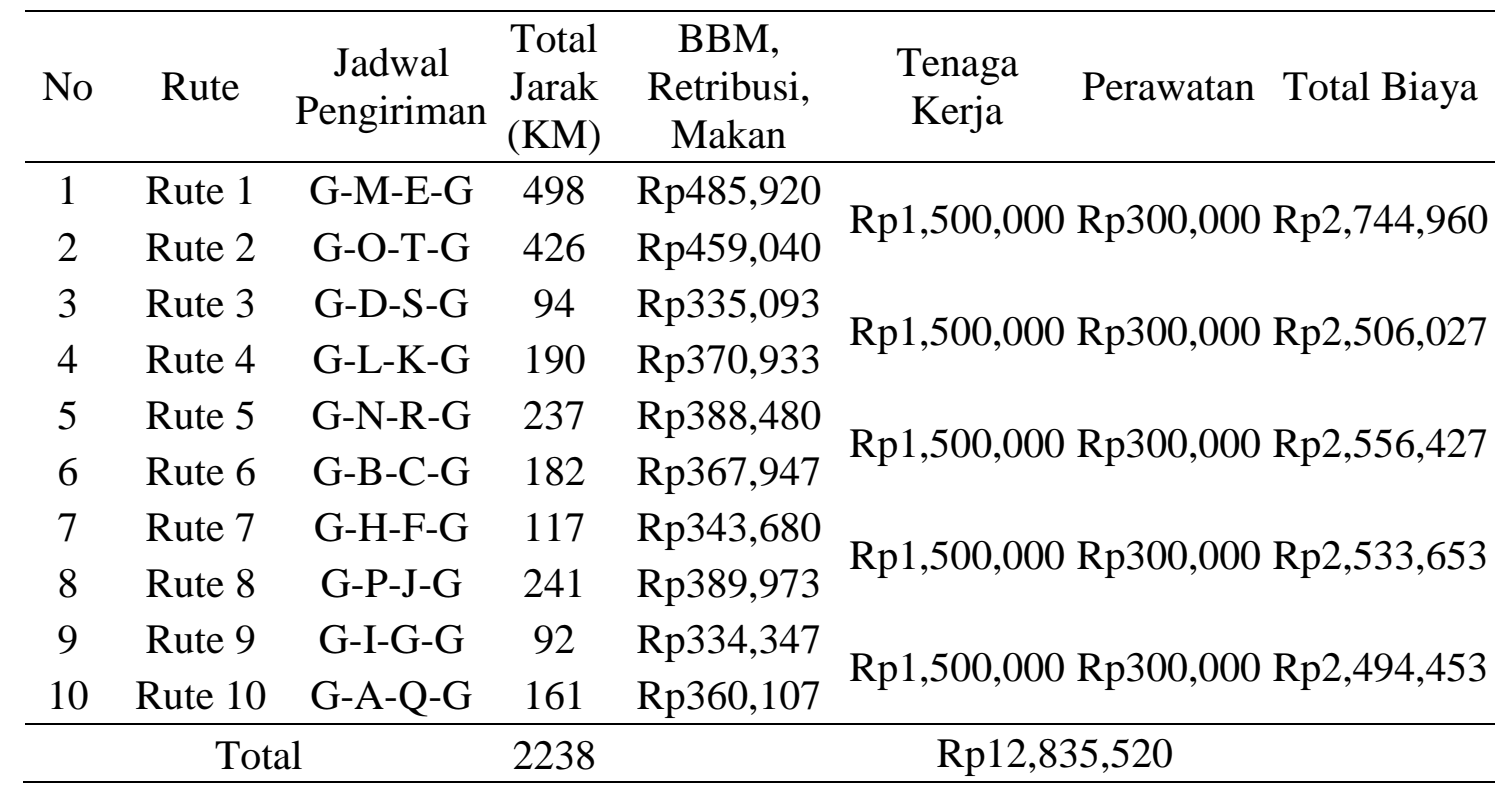

\section{PEMBAHASAN}

\section{Metode Peramalan}

Berdasarkan jenis dan pola data yang diperoleh yaitu pola trend, maka teknik peramalan yang dipilih dan akan dibandingkan adalah metode Regresi Linear Sederhana dan metode Hot's Linear Exponential Smoothing (Winter)., dan penetapan teknik peramalan terbaik adalah berdasarkan nilai MSE(Mean Square Error) terkecil.

Hasil peramalan berdasarkan dua metode yang digunakan menunjukkan bahwa peramalan dengan metode Regresi
Linear mempunyai nilai MAPE, MAD, dan MSE terkecil yaitu sebesar 0.50697, 0.102956, dan 0.018398. Perbandingan peramalan yang memiliki kesalahan peramalan terkecil tersebut akan digunakan sebagai informasi prediksi permintaan konsumen untuk periode selanjutnya (Tanuwijaya, 2010).

Proses verifikasi sangat dibutuhkan apabila sudah ditentukan metode peramalan yang digunakan. Verifikasi hasil peramalan diperlukan untuk melihat apakah metode peramalan yang diperoleh representative terhadap data atau tidak. 
Proses verifikasi dilakukan dengan menggunakan Moving Range Chart (MRC). Peta moving range digunakan untuk membandingkan nilai pengamatan aktual dengan nilai peramalan dari suatu permintaan. Pada penelitian kali ini, berdasarkan grafik 4.2, terlihat bahwa tidak ada data yang berada di luar batas kontrol atas maupun batas kontrol bawah. Dengan demikian, metode Linear Regression dapat dikatakan sesuai atau representatif terhadap penelitian ini dan dapat digunakan untuk meramalkan permintaan konsumen setahun ke depan.

\section{Penentuan Rute}

Penentuan rute distribusi produk dimulai dari proses pengidentifikasian matrik jarak. Proses ini memerlukan data jarak antara gudang ke masing-masing konsumen serta jarak antara konsumen satu dengan konsumen lainnya. Langkah selanjutnya adalah dengan cara mengidentifikasi matriks penghematan. Saving matrix merepresentasikan penghematan yang dapat direalisasikan dengan menggabungkan dua konsumen atau lebih ke dalam satu rute. Apabila masing-masing konsumen 1 dan konsumen 2 dikunjungi secara terpisah, maka jarak yang dilalui adalah jarak dari gudang ke konsumen 1 dan jarak dari konsumen 1 balik ke gudang, ditambah dengan jarak dari gudang ke konsumen 2 dan kemudian balik ke gudang. Ilustrasinya adalah seperti pada Gambar 3.

Gambar 3 merupakan kondisi proses distribusi awal di perusahaan. Perusahaan masih menerapkan pengiriman produk menggunakan satu jalur, yaitu dari gudang-konsumen1-gudang dan gudangkonsumen2-gudang. Kondisi tersebut dapat membuat proses distribusi produk menjadi lebih lama, jarak semakin panjang, dan biaya distribusi lebih banyak. Oleh karena itu, diperlukan perubahan rute yang dapat menggabungkan konsumen 1 dan konsumen 2 ke dalam satu rute. Gambar 4 adalah perubahannya. Gambar tersebut merupakan proses penggabungan rute yang terjadi, yaitu setiap satu rute dapat menempuh lebih dari satu konsumen, sehingga dapat menghemat jumlah rute, jarak, dan biaya distribusi.

Dengan berpedoman pada tabel matrik penghematan, proses pengalokasian konsumen dapat dilakukan. Pengalokasian setiap konsumen ke dalam satu rute dapat digabungkan sampai pada batas kapasitas alat angkut yang dimiliki perusahaan. Penggabungan tersebut dimulai dari nilai penghematan yang terbesar. Dimulai dari nilai penghematan sebesar 418 yang merupakan penghematan dari penggabungan antara konsumen $\mathrm{E}$ dan konsumen $\mathrm{M}$. Jumlah beban masingmasing konsumen adalah $7360 \mathrm{Kg}$ dan $6140 \mathrm{Kg}$, sedangkan total beban adalah $13500 \mathrm{Kg}$. Total tersebut masih di bawah batas maksimal kapasitas alat angkut, yakni $15000 \mathrm{Kg}$. Dengan demikian penggabungannya layak dilakukan, konsumen $\mathrm{E}$ dan konsumen $\mathrm{M}$ bergabung ke dalam rute 1 , dan begitu seterusnya.

Berikutnya adalah mengurutkan konsumen dalam rute yang sudah terdefinisi. Pada prinsipnya, tujuan dari pengurutan ini adalah untuk meminimumkan jarak perjalanan alat angkut. Penentuan rute dilakukan dengan metode Nearest Insert. Metode Nearest Insert dilakukan dengan cara memilih konsumen yang kalau dimasukkan ke dalam rute yang sudah ada menghasilkan tambahan jarak yang minimum. Pada awalnya hanya memiliki perjalanan dari gudang ke gudang dengan jarak nol, kemudian dilihat berapa jarak yang terjadi dengan cara menambahkan masing-masing konsumen ke rute yang sudah ada. Hasilnya adalah sebagai berikut:

$$
\begin{aligned}
& G-E-G=460 \mathrm{Km} \\
& G-M-G=456 \mathrm{Km}
\end{aligned}
$$

Berhubung jarak minimum yang dihasilkan dari keduanya adalah 456 kilometer, maka konsumen yang dikunjungi terlebih dahulu adalah konsumen M. Rute yang terbentuk adalah G-M-E-G, dan begitu seterusnya. 


\section{Perbandingan Rute dan Biaya Transportasi Awal}

Perbandingan rute distribusi produk sebelum diberlakukan metode saving matrix dan sesudahnya sangat jelas perbedaannya. Perbedaan tersebut ditampilkan pada Tabel 13.

Pada awalnya, perusahaan memiliki 20 rute dalam sekali pengiriman produknya. Jumlah rute tersebut dinilai sangat banyak mengingat jumlah armada atau alat angkut yang dimiliki perusahaan sangat terbatas. Total jarak yang ditempuh perusahaan selama proses pengiriman produk pada 20 konsumennya adalah sebanyak 3890 kilometer. Hal tersebut membuat biaya distribusi produk di perusahaan juga tidak sedikit, yaitu sebesar Rp. 22.952.267.Setelah diberlakukan metode saving matrix, jumlah rute, total jarak, dan biaya distribusi produk di perusahaan mengalami penurunan yang signifikan. Seharusnya rute distribusi produk tersebut dapat dipangkas menjadi 10 rute dari 20 rute mula-mula. Selain itu, perusahaan berhasil menurunkan jarak tempuh sebesar 1745 kilometer atau 55.77 $\%$.Biaya distribusi produk juga mengalami penghematan sebesar Rp10.151.467 atau $55.14 \%$.

\section{Perbandingan Rute dan Biaya Transportasi Usulan}

Peramalan digunakan untuk menentukan prediksi permintaan konsumen selama setahun ke depan. Dengan adanya peramalan, perusahaan dapat membuat jadwal distribusi produknya menggunakan metode Saving Matrix. Tujuannya adalah untuk memperpendek rute distribusi, jarak, dan menghemat biaya transportasinya. Output yang dihasilkan nantinya adalah usulan rute distribusi terbaru. Tabel 14 adalah perbandingan jumlah rute, jarak, dan biaya mula-mula dengan hasil peramalan.

Berdasarkan hasil peramalan dan penentuan rute distribusi dengan menggunakan metode Saving Matriks, jumlah rute yang didapat perusahaan turun dari 20 rute menjadi 10 rute. Jarak tempuh yang semula sebesar 3890 kilometer menjadi 2238 kilometer. Jarak tersebut lebih hemat $42.47 \%$ atau sekitar 1652 kilometer. Biaya distribusi produknya juga mengalami penurunan. Biaya semula adalah sebanyak Rp22.952.267 turun menjadi Rp12.835.830. Biaya tersebut mengalami penghematan sebesar Rp10,116,437atau sekitar $44.07 \%$.

\section{Usulan Rute Distribusi Produk}

Dari hasil pengolahan dan analisis data di atas, maka jumlah rute yang harus ditempuh Bunga Bangsa Co.Group untuk mendistribusikan produknya selama setahun ke depan adalah sebanyak 10 rute. Rute tersebut dikelompokkan sesuai hasil pengolahan data dengan menggunakan metode Saving Matrix. Usulan penentuan rute distribusi produk di Bunga Bangsa Co adalah seperti pada Tabel 15.

Berdasarkan Tabel 15, maka usulan untuk rute distribusi produk di Bunga Bangsa Co.Group sudah terbentuk. Total rute yang harus ditempuh untuk pengiriman produk adalah sebanyak 10 rute dengan kapasitas muatan sekitar $15000 \mathrm{Kg}$. Setiap rute memiliki tujuan konsumen yang berbeda-beda. Pengelompokan konsumen tersebut berdasarkan alokasi matriks penghematan tertinggi dengan metode Saving Matrix. Nilai savings berpengaruh pada penghematan total jarak. Semakin besar nilai savings yang didapat, maka semakin banyak penghematan total jarak yang diperoleh. Selain itu, semakin pendek total jarak yang ditempuh, maka semakin kecil waktu yang ditempuh (Ramadanti, et al., 2013).

\section{PENUTUP}

\section{Kesimpulan}

1. Rute pengiriman produk yang paling tepat untuk meminimalkan biaya transportasi/distribusi pada perusahaan-perusahaan angkutan kayu gelondongan di bawahBunga Bangsa Co.Group dapat direduksi menjadi sejumlah 10 rute dari 20 rute semula. 
2. Jarak rata-rata untuk menyalurkan barang yang harus ditempuh adalah sejauh 2238 kilometer dengan biaya transportasi sebanyak Rp. 12.835.830. Dengan demikian, perusahaan dapat menghemat jarak sebesar $42.47 \%$ atau 1652 kilometer dan dapat mengurangi biaya distribusi pengiriman produk hingga mencapai $44.07 \%$ atau sebesar Rp. 10.116.437.

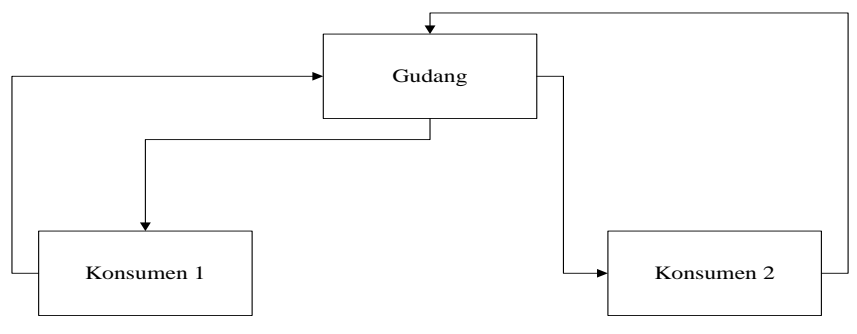

Gambar 3. Ilustrasi 1

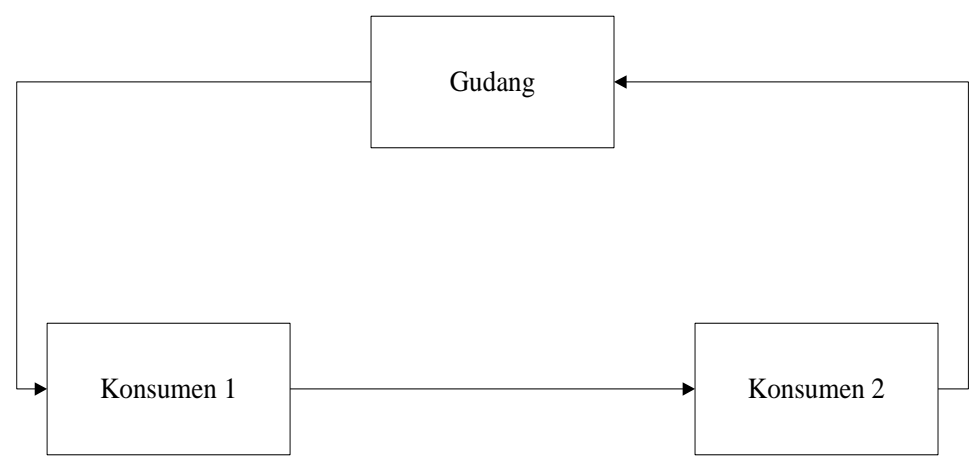

Gambar 4. Ilustrasi 2

Tabel 13. Perbandingan Rute Distribusi Awal

\begin{tabular}{lccccc}
\hline \multicolumn{1}{c}{ Item } & $\begin{array}{c}\text { Jumlah } \\
\text { Rute }\end{array}$ & $\begin{array}{c}\text { Total Jarak } \\
(\mathrm{Km})\end{array}$ & Total Biaya & $\begin{array}{c}\text { Penghematan } \\
\text { Biaya }\end{array}$ & $\begin{array}{c}\text { Penghematan } \\
\text { Jarak }(\mathrm{Km})\end{array}$ \\
\hline Sebelum & 20 & 3890 & $\mathrm{Rp} 22,952,267$ & $\mathrm{Rp} 10,151,467$ & 1745 \\
Sesudah & 10 & 2145 & $\mathrm{Rp} 12,800,800$ & $55.14 \%$ & $55.77 \%$ \\
\hline
\end{tabular}

Tabel 14. Perbandingan Rute, Jarak, Biaya Hasil Peramalan

\begin{tabular}{lccccc}
\hline & $\begin{array}{c}\text { Jumlah } \\
\text { Rute }\end{array}$ & $\begin{array}{c}\text { Total Jarak } \\
(\mathrm{Km})\end{array}$ & Total Biaya & $\begin{array}{c}\text { Penghematan } \\
\text { Biaya }\end{array}$ & $\begin{array}{c}\text { Penghematan } \\
\text { Jarak }(\mathrm{Km})\end{array}$ \\
\hline Sebelum & 20 & 3890 & $\mathrm{Rp} 22,952,267$ & $\mathrm{Rp} 10,116,437$ & 1652 \\
Sesudah & 10 & 2238 & $\mathrm{Rp} 12,835,830$ & $44,07 \%$ & $42,47 \%$ \\
\hline
\end{tabular}


Tabel 15. Usulan Rute Distribusi

\begin{tabular}{cccccc}
\hline No & Rute & $\begin{array}{c}\text { Jadwal } \\
\text { Pengiriman }\end{array}$ & $\begin{array}{c}\text { Total Jarak } \\
(\mathrm{KM})\end{array}$ & $\begin{array}{c}\text { Total Beban } \\
\text { Order }(\mathrm{KG})\end{array}$ & $\begin{array}{c}\text { Alat } \\
\text { Angkut }\end{array}$ \\
\hline 1 & RUTE 1 & G-M-E-G & 498 & 13720 & TRUK A \\
2 & RUTE 2 & G-O-T-G & 426 & 10540 & TRUK C \\
3 & RUTE 3 & G-D-S-G & 94 & 13070 & TRUK C \\
4 & RUTE 4 & G-L-K-G & 190 & 12760 & TRUK A \\
5 & RUTE 5 & G-N-R-G & 237 & 10960 & TRUK A \\
6 & RUTE 6 & G-B-C-G & 182 & 11010 & TRUK B \\
7 & RUTE 7 & G-H-F-G & 117 & 10180 & TRUK B \\
8 & RUTE 8 & G-P-J-G & 241 & 14240 & TRUK C \\
9 & RUTE 9 & G-I-G-G & 92 & 10590 & TRUK B \\
10 & RUTE 10 & G-A-Q-G & 161 & 14120 & TRUK B \\
\hline
\end{tabular}

\section{DAFTAR PUSTAKA}

Badria, (2008). Penggunaan Metode Exponential Smoothing Untuk Meramalkan Kebutuhan Cengkeh di Pabrik Rokok Adi Bungsu, Malang: Universitas Brawijaya.

Erlina, P. (2009). Mengoptimalkan Biaya Transportasi Untuk Penentuan Jalur Distribusi. Jurnal Penelitian Ilmu Teknik, 9(2), 143-150.

Rahmayanti, D., \& Fauzan, A. (2016). Optimalisasi sistem persediaan bahan baku karet mentah (lateks) dengan metode Lot Sizing (studi kasus: PT Abaisiat Raya). Jurnal Optimasi Sistem Industri, 12(1), 317-325.

Heizer, J. \& Render, B., (2010). Manajemen Operasi Edisi 9 Jilid 2. Jakarta: Salemba Empat.

Istantiningrum, M. (2010). Penentuan Rute Pengiriman Dan Penjadwalan Dengan Menggunakan Metode Saving Matrix Study Kasus Pada PT. Sukanda Djaya Yogyakarta. Yogyakarta: Program Studi Teknik Industri UIN Sunan Kalijaga.
Kadir, A. (2006). Transportasi: Peran dan Dampaknya Dalam Pertumbuhan Ekonomi Nasional. Jurnal Perencanaan \& Pengembangan Wilayah WAHANA HIJAU, 1(3), 121-131.

Kalekar, P. S. (2004). Time Series Forecasting using Holt-Winters Exponential Smoothng. Kanwal Rekhi School of Information Technology, 4329008, 1-13.

Pakaja, F., Naba, A. \& Purwanto. (2012). Peramalan Penjualan Mobil Menggunakan Jaringan Syaraf Tiruan an Certainty actor. Jurnal EECCIS, 6(1), 23-28.

Raharja, A., Angraeni, W. \& Vinarto, A. R. (2013). Penerapan Metode Exponential Smoothing Untuk Peramalan Penggunaan Waktu Telepon di PT. Telkomsel Surabaya. SISFO-Jurnal Sistem Informasi, 1-9.

Setyawan, B. (2012). Analisis Jaringan Transportasi Multimoda Dalam Proses Distribusi (Studi Kasus di PT. LMN). Yogyakarta: Prodi Teknik Industri Universitas Islam Negeri Sunan Kalijaga. 
Soedjianto, F., Oktavia, T. \& Anggawinata, A. J. (2006). Perancangan dan Pembuatan Sistem Perencanaan Produksi (Studi Kasus Pada PT. Vonita Garment). Seminar Nasional Aplikasi Teknologi Informasi ISSN 1907-5022, 117-122.

Tanuwijaya, H. (2010). Penerapan Metode Axponential Smoothing Winter Dalam Sistem Informasi Pengendalian PErsediaan Produk dan Bahan Baku Sebuah Cafe. SemnasIF ISSN 1979-2328, 219225.

Vandiko, G., Adianto, H. \& Mustofa, F. H., 2013. Usulan Rancangan Rute Distribusi Produk Sepatu Menggunakan Metode Vehicle Routing Problem. Jurnal Industri Itenal - ISSN: 2338-5081, 1(1) . 